\title{
A REVIEW \\ Role of cytological markers for evaluation of genetic integrity of in vitro regenerated plants
}

\author{
MANISH CHITTORA AND ARADHANA SUKHWAL
}

\author{
Department of Dairy and Food Microbiology, College of Dairy and Food Science Technology, Maharana Pratap \\ University of Agriculture and Technology, UDAIPUR (RAJASTHAN) INDIA \\ Email : mnshchittora@yahoo.co.in
}

Article Info : Received : 07.04.2016; Accepted : 20.09.2016

Key words : Cytological marker, Somaclonal variation, Genetic fidelity, Tissue culture

How to cite this paper : Chittora, Manish and Sukhwal, Aradhana (2016). Role of cytological markers for evaluation of genetic integrity of in vitro regenerated plants. Asian J. Bio. Sci., 11 (2) : 313-316.DOI : 10.15740/HAS/AJBS/11.2/313-316.

Micropropagation can be rewarding only if complete genetic fidelity of micropropagules is maintained. Genetic fidelity is the maintenance of genetic constitution of a particular clone throughout its growth span (Chatterjee and Prakash, 1996). Periodic monitoring of the degree of genetic stability of in vitro conserved plants is of utmost importance for commercial utilization of true-to-type plants of the desired genotype (Mohanty et al., 2011). The assessment of the genetic integrity of in vitro grown regenerants in regular intervals can significantly reduce or eliminate the chance of occurrence of somaclonal variation (Larkin and Scowcroft, 1981) at early or late phase of culture. Many factors are known to be associated with the occurrence of somaclonal variation which affect genetic fidelity of tissue culture plantlets, particularly when they are maintained for prolonged duration. These factors include genotype, age of donar plant, explants type (Haisel et al., 2001 and Peredo et al., 2008), plant growth regulators in the culture medium (Bairu et al., 2006) and number of subcultures (Chatterjee and Prakash, 1996 and Gangopadhyay et al., 2003). Skirvin et al. (1994) stated that the level of genetic variation that should be expected in in vitro culture is about 1-3 per cent.
Phenotypic variability among cell and tissue culturederived regenerants may be attributed to epigenetic, genetic, and chromosomal changes induced by the culture conditions (Evans and Reed, 1981; Sibi, 1984; Evans et al., 1984; D'Amato, 1985; Karp, 1986; Vasil, 1988; Stelly, 1989; Wersuhn, 1989; Oono, 1991 and Skirvin, 2000). The culture-induced variants have been termed "calliclones" (Skirvin and Janick, 1976 and Skirvin, 1978), "protoclones" (Shepard et al., 1980), and a widely used term "somaclones" (Larkin and Scowcroft, 1981).

The frequency of somaclonal variation is at a higher rate (upto $10 \%$ per cycle of regeneration) than chemicalor radiation-induced mutation.This makes somaclonal variation a viable alternative to mutagenesis and a valuable tool for a plant breeder to introduce variation into breeding programs (Skirvin, 2000). Epigenetic variations are due to the results of culture stress and these variations are not transmitted from generation to generation. Thus, these changes are acquired traits and are not genetically controlled.

The genetic variations are induced during culture due to single nuclear gene mutations. The mutants exhibit Mendelian inheritance. A large number of plant species have been regenerated from cell and tissue cultures 